\title{
On the Cultivation of Creative Design Talents in West Straits Culture and Creative Industry Chain
}

\author{
Wang Tingting \\ Xiamen University Tan Kah Kee College \\ Zhang Zhou, China \\ wellyuki@126.com
}

\begin{abstract}
In the background of the opening and development of the economic zone on the west side of the Straits, the paper explores how creative design higher education adapt to and cooperate with the inherent needs of the rapid development of cultural and creative industries in the region, develop advantageous brand and organizational vitality, and build a design education system of the west-straits characteristics which can meet the needs of the creative industry chain quickly, on the basis of the lack of strategic power in the creative design of higher education internationalization, the unclear role in the west-straits strategy, and the poor ideology of the development of disciplines. In the terms of the complexity and comprehensiveness of cultural and creative design industry chain, this paper summed up the design talent system the cultural and creative industries required and built the creative design talent training model to help the economic restructuring and upgrading of the west-straits region.
\end{abstract}

Keywords-west-straits; cultural industry chain; demand for talents; creative design talent training

\section{INTRODUCTION}

From 2009 onwards, the creative industry rose to China's national strategy. In the thirteen five plan of Fujian Province, the development of cultural industries elevated a new height. As the main body of the west-straits Economic Zone, Fujian is in the crucial period of economic structure and industrial restructuring, in which the development of cultural and creative industries occupies a very important position. Its development objectively requires the support of higher education to a certain extent, especially on a variety of creative design talent.

Throughout the high creative design talent training in the west-straits region, on a macro level, there are problems such as the lack of strategic power in the creative design of higher education internationalization and the unclear role in the weststraits strategy; on a micro level, there are problems such as the poor ideology of the development of disciplines. The lack of talent in the development of creative industries has formed a bottleneck restricting its development. Compared with the vigorous development of cultural and creative industries in the west-straits region, it is necessary to systematically meet the needs of the design talents and effectively promote the sound development of the creative industries.

\section{ANALYSIS ON THE BACKGROUND OF TALENT DEMAND FOR THE DEVELOPMENT OF CULTURAL INDUSTRY IN CROSS- STRAITS AREA}

The main body of cultural and creative industries in the cross-straits region includes two main categories: creative subject and communication subject. Cultural and creative products are mainly in the form of southern Fujian traditional technology, Dehua ceramics, online game portal, business stationery, animation creative research and development, animation education, creative business services, creative tourism, and other creative derivatives [1]. All of those are to recreate social values by creating wisdom and culture. The industrial contents are made up of the regularity featured by cultural creatives in the industrial sector and between the industrial sector. Based on that, the operational feature of industrial content is formed, and a long and wide industry chain relationship is formed in the relationship of industrial content operation.

The development of cultural and creative industries in the west-straits area includes two aspects: internal and external: on the one hand, under the background of the current cultural and creative industries, the development of west-straits cultural and creative industries is bound to be influenced by the negative impact of the contemporary cultural and creative industries (the current cultural and creative Industrial theory defects, the infeasible concepts in some areas, the social concerns brought by cultural and creative industries, etc.). On the other hand, the development of west-straits cultural and creative industries has its defects, including:

- A relatively weak cultural resources and the lack of high-end creative talents;

- The inadequate atmosphere of cultural interaction between the two sides of the Taiwan Straits;

- The lack of a complete industrial chain basis in creative cities;

- The lack of young cutting-edge groups as the main creator of creative atmosphere [2].

Among them, we can find that the negative impact caused by the lack of talents in the cultural development of the cross- 
straits region has become a major obstacle to its development of the cultural and creative industries.

From another perspective, in the field of higher education development, Design, as a professional to cultivate creative talents, becomes a first-level discipline in 2012. This objective development actually caused the prominent contradiction of backward development in the west-straits region. It is mainly due to the late development of disciplines throughout the country, which has been subordinate to the discipline of art. Even in the era where higher education has been popular now, the development of design disciplines, compared to other disciplines, are still weak, which is affected by China's socioeconomic development and the inaccurate positioning of design (design education, students dispute, the concept of contradictions, etc.).

The main problem in the development of the design education in the whole country (including the west-straits region) is that the educational philosophy of the design discipline is contradictory. On the one hand, it advocates to explore the self-regularity of design to make up for the late start of professional development. On the other hand, it continues to take the traditional elite education methods for the evaluation criteria, limiting the professional four-dimensional quality evaluation of interdisciplinary design. Not only that, people have the misunderstanding of innovative teaching. Under the premise of diversity, design creation (different from the artistic creation) prefers to workshop, studio, and projectbased educational organization without the process evaluation system. In this form of "reform and innovation", evaluation (standard) and essence (effect) formed the bottlenecks of higher education development in the design under the traditional, conservative, and contradictory teaching concept.

In summary, the talents background of the west-straits culture and creation industry development can be summarized as follows:

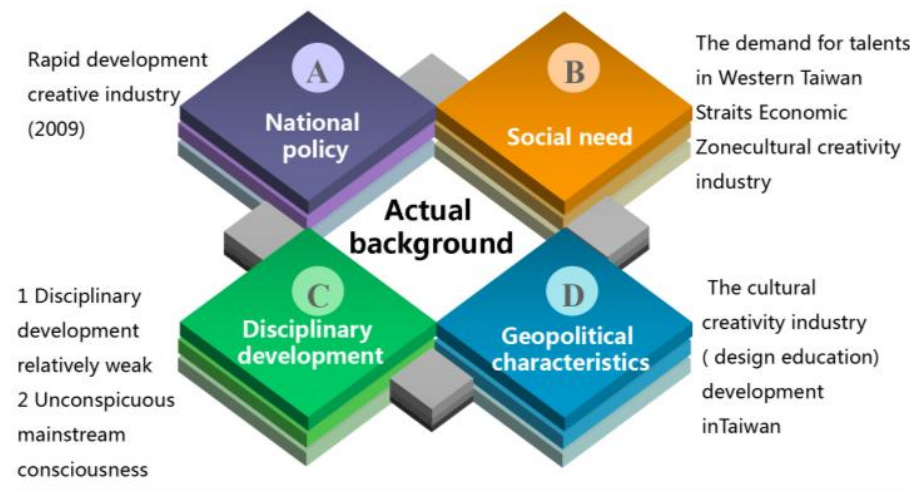

Fig. 1 The Talents Background Diagram of Cultural and Creative Industry in West-Straits Region

\section{THE SIGNIFICANCE OF TEACHING REFORM OF CREATIVE DESIGN SPECIALTY IN LOCAL COLLEGES AND UNIVERSITIES FROM THE PERSPECTIVE OF THE CULTURAL INDUSTRY CHAIN}

It is of great theoretical significance to reform the teaching of creative design in local colleges and universities from the perspective of docking the whole cultural industry chain. The locality and times of design specialty teaching are conducive to the development and construction of rich design cultural resources, as well as the inheritance and promotion of local special culture in industrial economy.

To study the cultivation of industrial chain docking ability in creation education design can better know the regional competitiveness and develop local culture. The cultural industry, as an important part of new industrial economy and economic transformation and upgrading, has the premise of value theory in the inheritance and innovation of culture. Therefore, the development of cultural industries in the region and even in the regional competition must meet the needs of its talent training system, which is the significance and purpose of the design teaching.

In the information age of pictures, to actively fight for the right to speak is the only way to expand the development and dissemination of regional culture, during which the rise and development of cultural and creative industries becomes an important means of regional marketing and new economic growth [7]. What we should do is to play the value of industry chain docking ability, talents promotion, in the education of design, make full use of modern information technology and educational innovation, and achieve the organic integration of creative design, cultural industries, and regional economy. Exercising the industry chain docking ability in the design teaching can help develop and construct rich design talent resources, which effectively spreads the new ideas and strategies in the development of cultural industries to the world[8].

Compared with the blossoming cultural and creative industries in the cross-straits region, what we lack is that whether the design talents we cultivated can support the demand of creative talents and how to effectively promote the sound development of the creative industries, which are essential to the cultural creative development and even the establishment of creative urban clusters in west-straits region.

According to scholar John Kings, the world's creative economy could create a daily value of 22 billion US dollars at a growth rate of 5\% [3]. To vigorously develop the creative industry policy, a national strategy, has an objective and practical needs to the organic integration of the creative industry talent training and cultural activities. With the background of the cross-straits region, it is of theoretical significance to explore and timely summarize the demand in this area.

The practical significance of the development of creative industries in the region lies in that in the background of the opening and development of the economic zone on the west side of the Straits, we should explore how creative design higher education adapt to and cooperate with the inherent needs of the rapid development of cultural and creative industries in the region, develop advantageous brand and organizational vitality, and build a design education system of the west-straits characteristics which can meet the needs of the creative industry chain quickly. As a result, we can form a sustained talent pool conditions for the development creative design career in the west-straits region and even the world. 


\section{THE CUlTurAL AND CREATIVE INDUSTRY CHAIN DOCKING ABILITY SYSTEM DEDICATED FOR DESIGN TALENTS}

Creativity, Innovation and Entrepreneurship are the three most important elements of the knowledge economy. They are also the focus of the teaching and research of design education in the development of cultural and creative industries. However, the three elements are only on the shallow requirements for the talents training of cultural and creative industries. If we want the sound development of the west-straits region's creative industry chain, we need develop the qualified personnel system for design talents in this region.

"The industrial chain is a concept in industrial economics, which is an image description of the interrelationships between the industrial sectors based on technical and economic ties. [4]" The so-called creative talents in a true sense refer to those with the independent intellectual property rights as the core, the brain service as the features, and the professional or special skills as a means. They have in-depth understanding of the industry and make continuous innovation based on reality [5]. In the country, including the west-straits region, what we lack is those compound talents who are both familiar with creative design skills and knowledge, but also understand the industrial operation and trends among the vast majority of design talents.

Moreover, the innovation of the creative design talents embodied in a certain quality of the original ability. Not only that, they can create individually or collectively with the insight into the prospect of innovative market [6], as well as the continuous innovation (curiosity, insight, learning ability, creativity, promotion and influence, etc.).

According to the comprehensive analysis, taking the main body of cultural industries, its forms, and the geographical characteristics of Fujian and Taiwan in the west-straits area into consideration, the cultural design talents need to have three abilities: the ability to solve the contradictions of different innovative design projects; the comprehensive design ability with the rational thinking and the emotional design; the ability of teamwork and rapid integration into the various types of creative design projects. They must have the ability to "rapidly dock creative industry chain" and from that gain sustained power with "creatives and rationality" in their jobs.

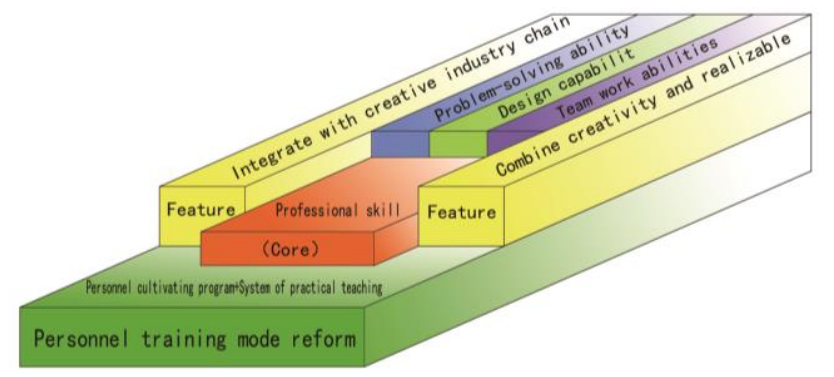

Fig. 2 Talent Training Model Reform Ability Map Fit for Creative Design Talents

\section{Personnel Training Program Conforming to the INHERENT NEEDS OF CULTURAL AND CREATIVE INDUSTRIES}

According to the characteristics of the regional culture in the west-straits region and the actual development of the cultural industry, the curriculum system and the personnel training program must be developed so that the cultivated talents can rapidly dock creative industry chain and practice the principle of creation and rationality, which is consistent with the personnel training program in the region's cultural and creative industries.

Creative design higher education is the basic source of training and supplying cultural and creative talents. Creative design graduates from colleges and universities work for the various agencies in the cultural industry chain, which is an important trend in the field of talent flow. The cultural and creative industries require the simultaneous development of creative design education and economic development, achieving the organic integration of technology, products, and markets. At the same time, the cultural elements in the cultural and creative industries must be highlighted. Creative design education must emphasize the cultivation of humanities, science and technology and so on, constantly improving the humanistic accomplishment of professional students, the artistic aesthetic ability, the artistic creation ability and the cultural communication ability. At the same time, the innovative education of design should highlight the application capacity of students to help students to associate professional knowledge with real life, solve practical problems, and stimulate students' cultural and scientific research ability and independent innovation ability in the practice system.

Therefore, personnel training program conforming to the inherent needs of cultural and creative industries can be summarized as follows:

\section{A. Training Concept}

We make it clear that "teaching serves the upgrading of cultural industries in the west-straits area, schooling serves its economic development, and we strive for a domestic first-class independent college design specialty with both international vision and local characteristics.

\section{B. Training Objectives}

We cultivate skillful and applicable design talents who in the market economy conditions can adapt to the needs of economic construction and social development in the $21 \mathrm{st}$ century; develop well in moral, intellectual, physical and aesthetic aspects; have access to the basic training of creative designers; have a broad basic theory, professional knowledge, strong professional skills and computer-aided design capabilities; can be integrated into various work in the professional industry chain. 


\section{Capability Requirements}

\section{1) Knowledge Structure}

- To systematically learn design basic theory, master the design method, plastic arts, as well as the production process of design, and know the basic methods and skills of design principles and the specific project design.

- To understand the basic facts of the professional design history and its development law, to study the relationship between psychology, life needs and behavior on the one hand and the design object on the other hand; learn related knowledge on economy, society, cultural practices, marginal disciplines and interdisciplinary areas; and have the cultivation of design aesthetics and art;

- To be familiar with the national and local design management and production and sales, intellectual property rights policies, regulations and systems;

- To have an initial master of a foreign language with a certain ability to read and write.

\section{2) Professional Competence}

- Through a reasonable set-up of professional courses and practical teaching links, talents can master the basic principles and methods of creative design with the independent development ability of creative design and the expression ability of the design intent in a variety of ways.

- To master the design form, the design and production system, the function and use of design object, and the basic knowledge of the application and aesthetics; master the development and production promotion of the design object and the scientific knowledge of design object domain; have the ability to choose the corresponding design object and use the object to implement design program.

- To develop the project research, draw the project design drawings, and present the whole process of design with the inter-species organization and coordination capacities.

- To skillfully use network technology and master computer-aided design skills with a preliminary computer text, graphics, data processing capacity;

- To complete the whole school system with the work ability to deal with different related business in the professional industry chain.

\section{Course System:}

- Basic theory and skills courses: Humanity History and Theory, Art Courses and Design Basic Courses;
- Professional project design courses: Thematic Design (series), Practice Platform (series), Industrial Chain Docking Courses (set up according to the professional characteristics);

- Main practical teaching courses: Comprehensive Social Practice, Design Awareness and Research, Cutting-edge Research, Project Practice, Computer-Aided Design, Graduation Design and so on.

\section{CONCLUSION}

With the acceleration of economic transformation, the regional development opportunities of the west-straits cultural and creative industries have gradually emerged. In the new period, the cultural and creative industries in the west-straits region can achieve further development, which require a large number of innovative creative talents with comprehensive knowledge, comprehensive ability and quality. We should explore how creative design higher education adapt to and cooperate with the inherent needs of the rapid development of cultural and creative industries in the region, develop advantageous brand and organizational vitality, and build a design education system of the west-straits characteristics which can meet the needs of the creative industry chain quickly. Based on the ability system designated for design talents in this cultural industries, we should build the creative design talent training model to help the economic restructuring and upgrading of the west-straits region, thereby ensuring the sources of talents for the blossoming cultural and creative industries.

\section{REFERENCES}

[1] Gao Xian. Zhang Yanxia. Study on Policy Support and Regulation Guarantee of Cultural and Creative Industry in the West-Straits Region [J]. Modern Marketing, $152 \sim 153$.

[2] Xiang Guangyi. The Challenges and Opportunities on the Cultural and Creative Industry in the West-Straits Region [J]. Journal of Xiamen University of Technology, 2012 (3): $38 \sim 42$.

[3] HOWKINS J. The creative economy - how people make money from ideas [M]. Anen Lane: Penguin Press,2001.

[4] Zeng Xianda. An Effective Way to Promote Regional Economic Development Based on the Advantages of Industrial Chain [J]. Academic Exchange, 2007 (9): 100 102.

[5] Luo Chaoyang, Wang Weizhong. Analysis on the Colleges Design Talents Training in the Cultural and Creative Industries [J]. Packaging World, 2010 (04): $58 \sim 62$.

[6] Zhu Lingyu. Exploration on the Talents Training Model Based on the Creative Industry Chain [J]. Journal of Hubei Normal University (Social Science Edition), 2014 (2): 133 135.

[7] (English) Charles Landley. Yang Yinglan (translator). Creative City: How to Create Urban Creative Life Circle [M]. Beijing: Tsinghua University Press, 2009.10.

[8] Zhang Aizhong. Thoughts on the Training and Employment of Cultural and Creative Industry Design Talent [J]. Dongjiang Journey, 2014 (01): $58 \sim 62$. 